BBA $5555^{6}$

\title{
EFFECTS OF ETHYLENIC BOND POSITION UPON ACYLTRANSFERASE ACTIVITY WITH ISOMERIC CIS-OCTADECENOYL COENZYME A TIIIOL ESTERS*
}

RONALDC. REITZa, MUSTAFA EL-SHEIKHa, WILLIAM E. M. LANDS ${ }^{a}, 1$ A. ISMAIL ${ }^{a}$ AND FRANK D, GUNSTONE

a University of Michigan, Department of Biological Chemistry, Ann Avbor, Mich. 48 ro4 (U.S.A.) and ${ }^{\mathrm{b} C h e m i s t r y ~ D e p a r t m e n t, ~ S t . ~ S a l v a t o r ' s ~ C o l l e g e, ~ U n i v e r s i t y ~ o f ~ S t . ~ A n d r e w s, ~ S t . ~ A n d r e w s ~}$ (Great Britain)

(Received November 22nd, 1968)

SUMMARY

The specificity of the acyl-CoA :phospholipid acyltransferases has been studied using the 16 positional isomers of cis-octadecenoic acid. The results showed that the acyl-transferases acting at both the I- and 2-positions of acyl-glycero-3-phosphorylcholine (acyl-GPC) discriminated between the acyl-CoA isomers in quite different ways.

r. Acyl-CoA:I-acyl-GPC acyltransferase activity showed a distinct preference for the 9 , and 12 -isomers. Of these three, the g-octadecenoate (oleate) was the preferred substrate having a rate of 98 nmoles/min per $\mathrm{mg}$.

2. Acyl-CoA:2-acyl-GPC acyltransferase reacted more rapidly with the 8-, ro-, I2-, I3- and I5-isomers, and of these the I2-octadecenoate had the fastest rate (I2I nmoles/min per $\mathrm{mg}$ ).

3. As the enzymes were allowed to age at $4^{\circ}$, the activity was lost at slightly different rates for each isomer. The enzyme(s) esterifying the I-position seemed to loose activity fairly uniformly with all isomers so that a similar pattern of reactivities was observed over a period of several days. The enzyme(s) esterifying the 2-position, however, differed in that after 2 days, the rate for the 9 -isomer had dropped below that for the I2-isomer. This result suggests that different enzymes may exist for different acyl-CoA isomers.

4. High concentrations of sucrose $(0.8 \mathrm{M})$ tended to stabilize the activities with the 9 - and 12 -isomers, but did not change the fact that the activity for the 9 -isomer was lost more rapidly. Albumin, contrary to our expectations, increased the rate of loss of activity.

5. The enzyme activities were purified I0- to 15 -fold above that of the crude tissue homngenate by treating the microsomal particles with sodium deoxycholate and albumin.

\footnotetext{
Abbreviations: GPC, glycero-3-phosphorylcholine; DTNB, 5, $5^{\prime}$-bisdithio(2-nitrobenzoic acid).

* This work was presented in part at the r.668 fall Meeting of the American Oil Chemists' Society.
}

Biochim. Rinphys. Acta, $176(1969) 480-490$ 
6. Acyltransferase rates for the esterification of the naturally occurring 7-, 9-, II-, and I3-octadecenoates to position I and 2 of diacyl-GPC indicated a preferred position for each acid which is in accord with that reported for the distribution of these monoenoic acids in phospholipids isolated from rat liver.

\section{INTRODUCTION}

The acyltransferase activities for the complete series of methylene interrupted cis,cis-octadecadienoic acids were recently reported'. The rates of reaction seemed to be influenced by combined effects of both ethylenic bonds rather than the existence of one ethylenic bond at some particular position.

LANDS et al. ${ }^{2}$ have shown that the distribution in vivo as well as in vitro of fatty acids between position I and 2 of diacyl-glycero-3-phosphorylcholine (diacyl-GPC) was influenced by the location and configuration of the ethylenic bond(s) within the fatty acid. JEZYK AND LANDS ${ }^{3}$ showed that the acyltransferase-catalyzed esterification of the I-position of the glycerolipid was dependent on the configuration of the 9-ethylenic bond, whereas the esterification of the 2-position was more dependent on the configuration of the 12 -ethylenic bond. The remarkable selectivity of the enzymes in response to the different positional isomers led us to investigate the acyltransferase specificities further by using the complete series of cis-octadecenoic acids. This simpler series would avoid combined effects of two bonds in one acyl chain. The results showed that the acyltransferases esterifying the I- and 2-positions of acyl-GPC discrimated between the positional isomers of octadecenoyl-Co $A$ in quite different ways. The relative activities for the 8-, 9-, and Io-isomers were surprisingly similar to those for the 8,II-, 9, I2-, and I0,I3-octadecadienoates.

In particular, the isomer containing a I2, I3-ethylenic bond, which could be regarded as enabling an octadecanoic acid to serve as an essential fatty acid, was handled in a manner quite different from the other positional isomers.

\section{MATERIAL AND METHODS}

\section{Synthesis of octadecenoic acids}

All of the cis-octadecenoic acids have been prepared and their purity checked by gas-liquid chromatography, by infrared spectroscopy, and by oxidative degradation ${ }^{4}$. The impurities in the preparations include traces of stearate, trans isomers, and positional isomers. The 2 -octadecenoic acid, prepared from palmitic acid via the $\mathrm{C}_{15}$-bromide and $\mathrm{C}_{12}$-alkyne, was $95 \%$ pure. The 3 -isomer ( $9 \mathrm{I}-93 \%$ pure) was obtained from 3-octadecynol, itself prepared by condensation of the lithium derivative of r-hexadecyne with ethylene oxide. The 4- to 9-octadecenoic acids were formed from condensation of the dimethylamides of alkynoic acids with an alkyl bromide, and the ro- to I2-isomers were prepared from I-alkynes and $\omega$-halogeno acid amides. All of these acids contained less than $\mathrm{I} \%$ impurity. The remaining acids (13- to I7-octadecenoic acids) were obtained from the corresponding $\mathrm{C}_{12}$-acids (7- to II-dodecenoic acids) by using the enamine process for chain-extension by six carbon atoms. These acids were contaminated mainly with their trans isomers and stearic acid: 13-octadecenoic acid (approx. 10\%); r4-octadecenoic acid (4-5\%); I5-octadecenoic acid 
$(5 \%) ;$ I6-octadecenoic acid $(2-4 \%) ;$ and 17 -octadecenoic acid $(6 \%)$. The methyl esters of these 5 acids were separated from the contaminants by chromatography on $\mathrm{AgNO}_{3}$-impregnated thin-layer plates. After the thiol esters had been prepared, the purity of the derivatives was checked by transesterification and gas chromatography on a column of $10 \%$ ethylene glycol succinate at $198^{\circ}$. All CoA thiol esters were greater than $97 \%$ pure except the 2 - and 3 -octadecenoates.

After the CoA thiol esters had been prepared, gas chromatography shewed that these two isomers were contaminated by three additional components which amounted to $50-60 \%$ of the total sample.

\section{Synthesis of acyl-CoA derivatives}

The acyl-CoA thiol esters of the cis-n-octadecenoic acids were synthesized by the micromodification of SEUBERT's procedure described by REITz ef al. ${ }^{1}, 30 \mu$ of each methyl ester were saponified in a solution of tetralnydrofuran-methanol ( $I$ : $I$, by vol.) containing $10 \% \mathrm{KOH}$ by heating it for $\mathrm{I} \mathrm{h}$ in a sand bath $\left(80^{\circ}\right)$ and then allowing it to stand overnight at room temperature. The solution was acidified to about $\mathrm{pH} \mathrm{I-2}$ with additions of $3 \mathrm{M} \mathrm{HCl}$, and the free fatty acids extracted with hexane. The acid chlorides were prepared by treatment with oxalyl chloride and then used to form acyl-CoA as previously described: The acyl-CoA derivitives were quantitatively determined by comparing the phosphorus content ${ }^{6}$ and the absorbance at 260 and $232 \mathrm{~m} \mu$ (ref. 5) with the spectrophotometric measurement of the amount of mercaptan released by acyltransferase systems ${ }^{\dagger}$. Agreement between these values indicated that the synthesized material was $100 \%( \pm 3 \%)$ reactive.

\section{Enzymatic studies}

Liver microsomal preparations from rats and pigs were prepared by collecting the particles that sedimented between $20000 \times \mathrm{g}(20 \mathrm{~min})$ and $100000 \times \mathrm{g}(60 \mathrm{~min})$ from tissue homogenates in $0.25 \mathrm{M}$ sucrose containing I $\mathrm{mM}$ EDTA. These particles were rehomogenized once with $0.25 \mathrm{M}$ sucrose containing $\mathrm{I} \mathrm{mM}$ EDTA, centrifuged for $9 \cdot 10^{6} \mathrm{~g} \cdot \mathrm{min}$, resuspended and stored at $-15^{\circ}$. The protein content was estimated using a nomograph based on the values given by WARBURG AND CHRISTIAN ${ }^{8}$. The rat liver microsomal protein used in earlier studies (see Table II) was treated with DFP to inhibit the high "hydrolase" activity".

Further purification of the enzymes was obtained by treating the microsomal protein with sodium deoxycholate and albumin, $20 \mathrm{mg}$ of sodium deoxycholate in I $\mathrm{ml}$ of $0.25 \mathrm{M}$ sucrose containing I $\mathrm{mM}$ EDTA was stirred with $60 \mathrm{mg}$ of microsomal protein $(2-3 \mathrm{ml})$ for $5 \mathrm{~min}$, and then $60 \mathrm{mg}$ of albumin in $2 \mathrm{ml}$ of $0.25 \mathrm{M}$ sucrose containing I mM EDTA was added and stirred for Io min. This solution was layered over $1.5 \mathrm{ml}$ of $0.5 \mathrm{M}$ sucrose containing I mM EDTA and centrifuged for $9^{\circ}$ I $0^{6} \mathrm{~g}$. min. The $0.5 \mathrm{M}$ sucrose fraction was combined with the pellet, homogenized, and resedimented for $9^{\cdot} 10^{6} \mathrm{~g} \cdot \mathrm{min}$. This treated microsomal protein resulted in a Io- 15 -fold increase in acyltransferase activity above that in the crude liver homogenate.

Phospholipid substrates were prepared by selective hydrolysis" of diacylGPC and alkenyl acyl-GPC.

A typical acyltransferase reaction mixture contained $0.8 \mathrm{ml}$ of o.I $\mathrm{M}$ Tris- $\mathrm{HCl}$ buffer ( $\mathrm{pH} 7.4$ ), o.I ml of o.0I M 5,5'-bisdithio(2-nitrobenzoic acid) (DTNB), 30 
nmoles of acyl-CoA, $0.2 \mathrm{mg}$ of microsomal protein, and $0 . \mathrm{I} \mathrm{ml}$ of acyl-GPC (I75 nmoles of I-acyl-GPC or $200-300$ nmoles of 2 -acyl-GPC). As described earlier ${ }^{7}$, the acyltransferase rates were continuously recorded in a spectrophotometer using DTNB (ref. Io) to measure the released CoA. The endogenous rate observed without added acyl-GPC was subtracted to give a net rate of acyl transfer?

\section{RESULTS}

Table I shows that increasing the concentration of each thiol ester derivative, from 10 to $40 \mu \mathrm{M}$, did not significantly affect the rates of acyl transfer. For example, the values for the I2-isomer, which had the fastest rate, ranged from $28-32$ nmoles/ min per mg protein with microsomal Preparation A. This variation is within the experimental error. Table I also shows that these levels of acyl-CoA saturate the activity of the more highly purified enzyme. Only the 9-, I2-, and I5-isomers were tested with the purified enzyme and their activities remained essentially constant over the range of concentrations. The other members of the series were considered to behave similarly with the purified enzyme preparation, since the activities were

\section{TABLE I}

ACYL TRANSFER RATES WITH VARYING CONCENTRATONS OF ACYL-COA

Microsomal prep. A was treated with $D F P^{7}$. Microsomal preps. B and C were treated with deoxycholate and albumin and not with DFP. With microsomal preparations $A$ and $B$, the reaction mixture contained 575 nmoles of $\mathrm{I}$-acyl-GPC, varying concentrations of the indicated acyl-CoA and $0.2 \mathrm{mg}$ protein in a final vol. of $\mathrm{Iml}$ (see MATERIAL AND METHODs). Reaction mixtures with preparation $C$ contained $200-300$ nmoles of 2 -acyl-GPC instead of 1 -acyl-GPC. Since each assay involved a continual recording of the product formed each velocity reported represents an average of a large number of recorded determination. All values have been corrected for hydrolase activity ${ }^{7}$.

\begin{tabular}{|c|c|c|c|c|c|}
\hline \multirow{2}{*}{$\begin{array}{l}\text { Microsomal } \\
\text { preparation }\end{array}$} & \multirow{2}{*}{$\begin{array}{l}\text { Acyl-CoA } \\
\text { isomer }\end{array}$} & \multicolumn{4}{|c|}{ Acyl-transfer rale (nwoles $/$ min per $m g$ ) } \\
\hline & & $\overline{I O \mu M}$ & $20 \mu M$ & $30 \mu M$ & $40 \mu M$ \\
\hline \multirow[t]{16}{*}{ A } & 2 & 0 & 0 & 0 & $o$ \\
\hline & 3 & 0.9 & 0.4 & 0.4 & 0 \\
\hline & 4 & $\mathrm{I} \cdot 5$ & 1.3 & I. 2 & I. 5 \\
\hline & 5 & 2 & 4 & 3 & 3 \\
\hline & 6 & 0 & 1.0 & $0 . I$ & 0.1 \\
\hline & 7 & 0 & 0 & 0 & o \\
\hline & 8 & I & 3 & 3 & 5 \\
\hline & 9 & I3 & 15 & 15 & $\mathrm{I}_{4}$ \\
\hline & Io & 8 & 10 & ro & 8 \\
\hline & II & 6 & 7 & 7 & 7 \\
\hline & 12 & $3 I$ & 28 & $3^{2}$ & $3 I$ \\
\hline & $x 3$ & 18 & 18 & 19 & I7 \\
\hline & $I_{4}$ & 4 & 4 & 4 & 4 \\
\hline & $\mathrm{I}_{5}$ & 4 & 5 & 5 & 5 \\
\hline & $\mathrm{x} 6$ & 3 & 4 & 4 & 4 \\
\hline & 17 & 4 & 4 & 4 & 4 \\
\hline \multirow[t]{3}{*}{ B } & 9 & $5^{2}$ & 57 & 60 & 60 \\
\hline & I 2 & 70 & $8 \mathrm{~T}$ & 85 & 86 \\
\hline & 15 & 13 & I 2 & I 2 & 12 \\
\hline \multirow[t]{5}{*}{ C } & 8 & $4^{8}$ & $4^{8}$ & $4^{8}$ & $4^{6}$ \\
\hline & 9 & I3 & 12 & II & 9 \\
\hline & II & II & 14 & $\mathrm{I} 2$ & 14 \\
\hline & I 2 & 57 & $6 x$ & 58 & $4^{8}$ \\
\hline & 15 & $3 I$ & 41 & 47 & 47 \\
\hline
\end{tabular}


constant for these three isomers and for all the isomers with the crude enzyme preparation.

The bottom portion of Table I (microsomal preparation C) indicates that the rates of acyl transfer to the I-position were essentially unaffected by small increases in acyl-CoA concentration. A representative group of the acyl CoA isomers which had either slow or fast rates was selected. In certain instances, the rates decreased at an acyl-CoA concentration of $40 \mu \mathrm{M}$ (see the 9- and I2-isomers).

Fig. I indicates the relative acyl transfer rates of the complete series of octadecenoates when being esterified to the 2 -position of acyl-GPC. The three curves represent results obtained with different microsomal preparations. In all three cases, three isomers (the 5-, 9-, and I2-octadecenoates) had rates faster than their adjacent isomers. In the more active preparations, the 16 - and I7-octadecenoates had rates faster than the $I_{4}$ - and ${ }_{5} 5$-isomers. Curve a, which has the fastest rate for 9 -octadecenoate, was obtained with a freshly prepared, purified preparation of microsomal membranes. In this microsomal preparation, the activity for the 9-isomer was 2.4 times that of the I2-isomer; however, in the crude frozen microsomal preparation, Curve $c$, the activity for the 12 -isomer was 3.3 times that of the 9 -isomer. When the microsomal preparation used to obtain Curve a was stored $24 \mathrm{~h}$ at $4^{\circ}$ and the acyltransferase activities measured, Curve $b$ was obtained. The overall pattern of activities was similar to that in Curve a, but attention should be drawn to the interrelationship of the 9 - and 12 -isomers. The activity for the 9-isomer had decreased approx $50 \%$, whereas that for the 12 -isomer decreased only $20 \%$.

The relative instability of the activity for the 9-isomer is further illustrated in Fig. 2. Three samples of microsomes were purified according to the procedure listed in the experimental section; after which, the three pellets were homogenized

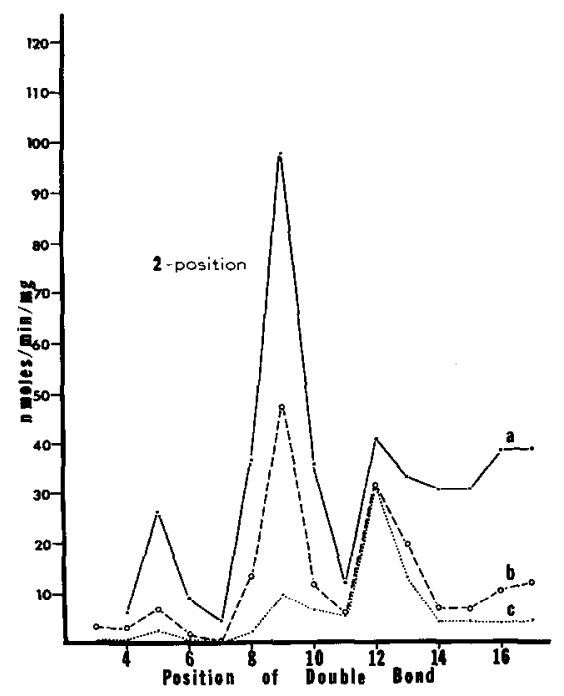

Fig. I. Acyltransterase specificities of difterent microsomal preparations from rat liver with Iacyl-GPC. The reaction mixtures contained 30 nmoles of acyl-CoA, 175 nmoles of I-acyl-GPC, and $0 . \mathrm{mg}$ rat liver microsomal protein for Curves a and $b$, and $0.2 \mathrm{mg}$ protein for Curve $\mathrm{c}$ in a final vol. of I ml (see MATERIAIS AND METHODS). Curve a was obtained with a freshly purified microsomal preparation. Curve b was obtained with the same microsomal preparation after $24 \mathrm{~h}$ storage at 4 . Curve $c$ was obtained with a "crude" microsomal preparation.

Biochim. Biophys: Acta, 176 (1969) $480-490$ 
in $0.8 \mathrm{M}, 0.25 \mathrm{M}$, and $0.25 \mathrm{M}$ sucrose, respectively. The protein content of each was measured and an equal amount of albumin was added to one of the suspensions in $0.25 \mathrm{M}$ sucrose. The activities were measured daily, and the microsomal suspensions were stored at $4^{\circ}$. In all cases, the I2-isomer became the most active substrate by the second day. However, when one compares the threc sets of curves, it becomes apparent that even though the cross-over point occurred between the first and second day, there was a distinct difference among the preparations in the rates at which activity was lost. The microsomal preparation which was homogenized in $0.8 \mathrm{M}$ sucrose was more stable towards both substrates than either of the other two preparations. Only $20 \%$ of the activity for the I 2 isomer was lost during the first 3 days, while during the same time period, $6 \mathrm{r} \%$ and $79 \%$ was lost in the $0.25 \mathrm{M}$ sucrose and $0.25 \mathrm{M}$ sucrose plus albumin preparations, respectively. The enzyme which transesterifies the 9-isomer was stabilized to a much lesser extent than the enzyme which transesterifies I2-octadecenoate by the $0.8 \mathrm{M}$ sucrose. It had lost $32 \%$ of its activity after the first day as compared to $45 \%$ and $65 \%$ for the enzyme preparation stored in $0.25 \mathrm{M}$ sucrose and $0.25 \mathrm{M}$ sucrose plus albumin, respectively.

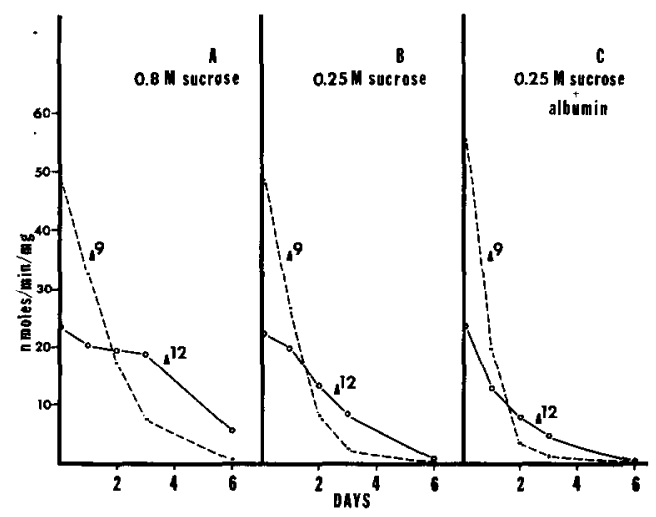

Fig. 2. Loss of activity of I-acyl-GPC: acyl CoA acyltransferase for 9- and I2-octadecynoyl CoA upon storage at $4^{\circ}$. A. The microsomal preparation was stored in $0.8 \mathrm{M}$ sucrose. $\mathrm{B}$. The microsomal preparation was stored in $0.25 \mathrm{M}$ sucrose. C. The microsomal preparation was stored in $0.25 \mathrm{M}$ sucrose with an added amount of albumin equal to the amount of microsomal protein. The three microsomal preparations were assayed at the time intervals indicated by mixing $30 \mathrm{nmoles}$ of acyl-CoA, I 75 nmoles of $\mathrm{I}$-acyl-GPC, and o. I $\mathrm{mg}$ microsomal protein in a final vol. of $\mathrm{I} \mathrm{ml}$ (see MATERIALS AND METHODS).

Fig. 3 represents results from studies on the acylation of the I-position of acylGPC using different rat liver microsomal preparations. In all cases, the rates of the 5-, 8-, 10-, I2-, and 15-octadecenoates were faster than either of the two isomers adjacent to them. Curve a was obtained using a freshly-prepared, purified microsomal fraction. With this preparation, the I2-isomer had the highest activity (I2I nmoles/ min per $\mathrm{mg}$ ) followed by the 8-isomer (104 nmoles/min per $\mathrm{mg}$ ). The I0- and 15isomers had similar activities $(67 \mathrm{nmoles} / \mathrm{min}$ per $\mathrm{mg}$ and $62 \mathrm{nmoles} / \mathrm{min}$ per $\mathrm{mg}$, respectively) while the 5-octadecenoate had only one quarter of this activity ( ${ }_{7}$ nmoles/min per $\mathrm{mg}$ ). Even though the I2-isomer had a faster rate than either of its two adjacent isomers, the $\mathbf{1 3}$-octadecenoate had the third fastest acyl transfer rate to the I-position (93 nmoles/min per mg).

This microsomal preparation was stored at $4^{\circ}$ for 3 days; after which the acyl 
TABLE II

COMPARISON OF ACYLTRANSFERASE SPECIFICITIES OF RAT AND PIG LIVER MICROSOMALP REPARATIONS FOR THE I- AND 2-POSITION

The reaction mixture contained 30 nmoles of acyl-CoA, I 75 nmoles of I-acyl-GPC or $200-300$ nmolcs of 2-acyl-GPC, and $0.2 \mathrm{mg}$ of rat or pig liver microsomes in a final vol. of $\mathrm{I} \mathrm{ml}$ (see experimental section). Each value represents the average of 6 to Io assays and standard deviations are given. These experiments were done prior to the recognition of the effect that aging has on the microsomes.

\begin{tabular}{|c|c|c|c|c|}
\hline \multirow{2}{*}{$\begin{array}{l}\text { Acyl-CoA } \\
\text { isomer }\end{array}$} & \multicolumn{2}{|l|}{$2-p o s i t i o n$} & \multicolumn{2}{|l|}{ I-position } \\
\hline & $R a t$ & Pig & Rat & $P i g$ \\
\hline 2 & $0.0 \cdots 0$ & o & $O=0$ & $O=O$ \\
\hline 3 & $0.3 \div 0 . \mathrm{I}$ & O.I & $0.1: 0.1$ & $0.9=0.3$ \\
\hline 4 & $0.8 \quad 0.2$ & 0.3 & $\mathrm{I} .4 \pm 0.4$ & $3.1=0.7$ \\
\hline 5 & 2.5 上 0.2 & $3.5 \pm \mathrm{I} .2$ & $8.9=I .4$ & $13.7-2.0$ \\
\hline 6 & $0.9 \pm 0.2$ & $0.8 \pm 0.2$ & $2.6=1.0$ & $5.5=I .2$ \\
\hline 7 & $0.0=0$ & $0.0=0$ & $7.7-12.0$ & I $8.4=3.5$ \\
\hline 8 & $2.3=0.3$ & $2.9 \quad 0.7$ & $30.1=3.6$ & 48.76 .1 \\
\hline 9 & $9.9: 0.8$ & $7.0=1.0 .6$ & $6.3 \pm 0.9$ & II.2 2.6 \\
\hline IO & $6.6=0.6$ & 6.4 上 1.8 & $2 \mathrm{I} .4 \pm 2.7$ & $22 . I=3.9$ \\
\hline I I & $5.7 \ldots 0.3$ & $5.3=1.7$ & 20.2 … 3.3 & $34.9 \therefore 4.1$ \\
\hline I 2 & $33.3=1.9$ & $22.2 \div 2.8$ & $33.4 \because 3.2$ & $44.8=2.9$ \\
\hline I 3 & $13.3 \pm 1.2$ & I I.2 $=! ! \ldots 2.0$ & $17.3=1.4$ & $28.5 \div I .5$ \\
\hline I4 & $4.3 \pm 0.3$ & $5.7=0.8$ & $25 . \mathrm{I} \pm 2.4$ & $34.8: 3.2$ \\
\hline I 5 & $4.4\rfloor_{-} 0.3$ & $5.8 \ldots .7$ & $15.5 \_1.8$ & $20.7: 1.2$ \\
\hline I 6 & $3.9: 1=0.3$ & $6.6 \pm 1.7$ & I $3.2=1.0$ & I6.0 I. I.4 \\
\hline 17 & $4.3+0.7$ & $3.3 \pm 0.7$ & $7 \cdot 4: 1-1.5$ & $12.0-2.2$ \\
\hline
\end{tabular}

transfer rates for the 7 -through the I6-isomers were measured again. The results are shown in Curve b. Each isomer seemed to loose activity at slightly different rates, but the same overall pattern of activity was maintained. This same pattern of activity was also obtained with crude, frozen microsomal preparations (Curve c). There was no selective loss of activity for transesterification of the different acids to the I-position of acyl-GPC.

Table II compares the results of acyltransferase studies with rat liver microsomes to those with pig liver microsomes. This table was included to show that microsomal membranes of different animal species have very similar acyltransferase specificities. In both species, the 5-, 9-, I2-octadecenoates had rates greater than their adjacent isomers when being transferred to the 2-position. When being transferred to the I-position, the 5-, 8- and I2-octadecenoates had rates faster than their adjacent isomers.

The standard deviations for some of the rates of the acyl-CoA's were quite large $(20-30 \%$ of the mean) because these studies were done prior to the recognition of the effects of ageing on the acyl transferases. The large deviations were a result of combining values from several different microsomal preparations. It should be pointed out that the deviations in the assays from one microsomal preparation were not large $(2-5 \%$ of the mean).

In Table III, the rate of transesterification to positions I and 2 of acyl-GPC are compared to the melting points of each of the monoenoic acids ${ }^{4}$. When the double hond was located at either end of the carbon chain, the melting points were high $\left(50^{\circ}\right)$; however, their values were alternatively low $\left(12^{\circ}\right)$ and high $\left(24^{\circ}\right)$ from the 5isomer through the I2-isomer. Interestingly, the rates of acyl transfer to the I-position followed a similar alternating scheme from the 7 - to the 13 -isomers. Isomers with ethylenic bonds at even-numbered positions were higher melting and more rapidly 


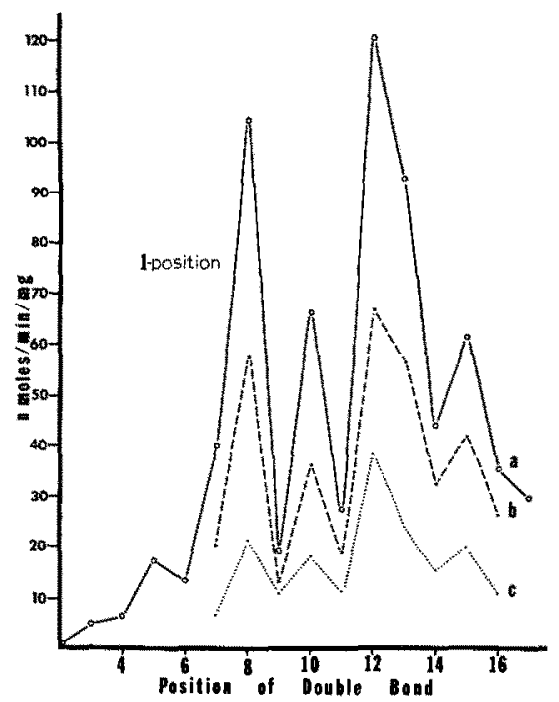

Fig. 3. Acyltransferase specificities of different microsomal preparations from rat liver with 2acyl-GPC. The reaction mixture contained 30 nmoles acyl-CoA, 175 nmoles 2 -acyl-GPC, and $0 . \mathbf{I}$ $\mathrm{mg}$ rat liver microsomal protein for Curve a and $\mathrm{b}$, and $0.2 \mathrm{mg}$ protein for Curve $\mathrm{c}$ in a final volof $1 \mathrm{ml}$ (see MATERIALS AND METHODS). Curve a was obtained with a freshly purified microsomal preparation. Curve $b$ was obtained with the same microsomal preparation after $7^{2}$ h storage at $4{ }^{\circ}$. Curve $c$ was obtained with a "crude" microsomal preparation.

TABLE III

COMPARISON OF THE MELTING POINTS OF THE MONOENOIC ACIDS WITH THEIR ACYL TRANSFER RATES

\begin{tabular}{|c|c|c|c|}
\hline \multirow{2}{*}{$\begin{array}{l}78: I \\
\text { isomer }\end{array}$} & \multirow{2}{*}{$\begin{array}{l}\text { Meling point } \\
\text { of acid* }\end{array}$} & \multicolumn{2}{|c|}{ Transfer rate } \\
\hline & & Position $x$ & Position \\
\hline 2 & $49.0-50.0$ & $\mathbf{I}$ & $o$ \\
\hline 3 & $49.5-50.5$ & 5 & 0.3 \\
\hline 4 & $45 \cdot 5-46.5$ & 8 & 6 \\
\hline 5 & $\mathrm{x} 2.5-13.5$ & 17 & 26 \\
\hline 6 & $28.0-29.0$ & I5 & 9 \\
\hline 7 & $12.0-13.0$ & 39 & 5 \\
\hline 8 & $23.5-24.0$ & 105 & 37 \\
\hline 9 & $10.0-I I .0$ & I9 & 98 \\
\hline 10 & $22.5^{-2} 3.5$ & 67 & 36 \\
\hline $\mathfrak{I I}$ & $12.5-13.5$ & 28 & 12 \\
\hline 12 & $27.0-28.0$ & $\mathrm{I} 2 \mathrm{~T}$ & $4^{x}$ \\
\hline 13 & $26.5-27.0$ & 93 & 33 \\
\hline 14 & $41.5-42.5$ & 44 & $3^{Y}$ \\
\hline$\times 5$ & $40.5-4 \times .5$ & 62 & $3 \mathrm{I}$ \\
\hline 16 & $53 \cdot 5-54.5$ & $3^{6}$ & 39 \\
\hline 17 & $55 \cdot 5-56.5$ & $3^{\circ}$ & 39 \\
\hline
\end{tabular}

* See ref. 4 .

esterified. However, comparing the rates of transesterification to the 2-position, only the $\mathrm{x} x-, \mathrm{Iz}-$, and $\mathrm{I} 3$-isomers followed an alternating pattern somewhat similar to the melting points. It should also be noted that the melting points of the I4- and I5-isomers were essentially identical $\left(4 I .5^{\circ}\right.$ and $40.5^{\circ}$, respectively) as were the acyl transfer rates to the 2-position ( $3 \mathrm{I}$ nmoles/min per $\mathrm{mg}$ ). As the double bond was placed at the 16 - and I7-positions, there was an increase in both the melting points 
$\left(53.5^{\circ}\right.$ and $55.5^{\circ}$, respectively) and the acyl transfer rates to the 2-position (39 nmoles/ min per $\mathrm{mg}$ ). Here again, the melting points of the acids were essentially identical as were the acyl transfer rates.

\section{DISCUSSION}

The results shown in Table I indicate that the acyltransferase rates were not influenced significantly by changing the acyl-CoA concentration from 40 to to $\mu \mathrm{M}$. Since the reaction mixture contains microsomal protein which can bind surfaceactive materials like acyl-CoA and acyl-GPC, we cannot accurately state the actual concentration of micellar or free monomeric acyl-CoA in the reaction mixture. However, one can say that the enzyme system was sufficiently saturated with substrate so that consumption of substrate during the early part of the reaction would not alter the rate. ZAHLER, BARDEN AND CLELAND ${ }^{11}$ have reported a critical micelle concentration for palmitoyl-CoA of 3-4 $\mu \mathrm{M}$. They stated that "if the free monomeric molecule is the active substrate, Michaelis kinetics will be observed only below the critical micelle concentration, and the initial velocity may be independent of substrate concentration above the critical micelle concentration".

Many studies have shown that the naturally occurring saturated fatty acids are selectively located at the I-position whereas unsaturated fatty acids are selectively located at the 2-position of phosphoglycerides ${ }^{12-14}$; however, the positional distribution for monoenoic fatty acids is not as clear-cut as that for the saturated and polyunsaturated fatty acids. Data exist which led to the suggestion that the incorporation of monoenoic fatty acids into either the I- or 2-position of phosphoglycerides is dictated predominately by the nutritional state of the animal ${ }^{14}$, thus precluding any real enzyme specificity. The data of LANDS et al. ${ }^{2}$ and WAKU AND LANDS ${ }^{15}$ have shown that the acyltransferases can be used to predict the distribution of fatty acids between the I- and 2-positions of diacyl-GPC in both rat liver and erythrocyte membranes. Recalculation of BROCKERHOFF AND ACKMAN'S data ${ }^{16}$ by multiplying the percentage of a given $\mathrm{r} 8$-carbon monoenoic isomer times the percentage of the total monoenoic acids at either the I- or 2-positions allows the comparison of the amount of each fatty acid at each position. BROCKERHOFF AND ACKMAN ${ }^{16}$ have analyzed animal glycerolipids for the positional distribution of several isomers of monoenoic fatty acids which are normal constituents of lipids. Their results clearly indicate that the $7^{-}, 9^{-}, \mathbf{I I}$, and 13 octadecenoic acids accumulate to different extents in both the I- and 2-positions. This distribution could reflect either the amount of each isomer present or enzyme specificity, or more probably a combination of both. There could also be competetion between the monoenes and the other fatty acids present in vivo for a given position of diacyl-GPC. The competitive effects which could occur with a mixture of acids has been discussed in some detail by LANDS et al. ${ }^{2}$. The present study demonstrates that there is a distinct enzyme specificity which lies in the acyltransferases. In Table IV a comparison is made between the amount of a monoenoic fatty acid present in the I- and 2 -positions of diacyl-GPC of rat liver and the acyltransferase rates for that isomer at these positions. Although the ratio between position $x$ and position 2 from the gas-liquid chromatography analysis did not agree quantitatively with that from the acyltransferase analysis, the qualitative comparison was quite similar. Here again, it appears that the acyl transferase activi- 
ties can be used as an index to the amount of a given fatty acid which will be found in the I- and 2-position of isolated diacyl-GPC molecules.

In studying the effects of temperature and solvents on the acyltransferases, JEZYK AND LANDS ${ }^{3}$ showed that the enzyme which esterifies the 2-position was quite sensitive to the configuration of the r2-ethylenic bond, whereas the enzyme which esterifies the I-position was more sensitive to the configuration of the 9 -ethylenic bond. The activities toward the cis-I2-ethylenic derivatives were retained while activity towards the cis-9-ethylenic bond was lost when ethylenic glycol was added to the system ${ }^{3}$. Even though this report is concerned with positional isomers and not with configurational isomers, similar changes occurred with the activities for the 9and I2-monoenes during storage at $4^{\circ}$. The cis-12-ethylenic bond, which seems to confer essentially to a fatty acid, was recognized by an enzymic activity which was maintained under a variety of environmental conditions in which activity towards

TABLE IV

INCORPORATIONS OF THE NATURALLY OCCURRING MONOENES INTO THE I-AND 2-POSITIONS OF DIACYL-GPC

Content: see ref. I5. Rate: spectrophotometric assay.

\begin{tabular}{|c|c|c|c|c|c|c|c|c|}
\hline \multirow{3}{*}{$\begin{array}{l}\text { Position } \\
\text { esterified in } \\
\text { diacyl-GPC }\end{array}$} & \multicolumn{8}{|c|}{ Location of ethylenic bond } \\
\hline & \multicolumn{2}{|l|}{7} & \multicolumn{2}{|l|}{9} & \multicolumn{2}{|l|}{$I I$} & \multicolumn{2}{|l|}{$I 3$} \\
\hline & Content & Rate & Content & Rate & Content & Rate & Content & Rate \\
\hline I & 0.49 & 39 & 2.73 & I6 & 3.15 & 28 & 0.56 & 93 \\
\hline 2 & 0.20 & 5 & 8.10 & 98 & 1.60 & I 2 & 0.10 & 33 \\
\hline
\end{tabular}

other positional isomers was lost; thus, relative comparisons of specific activity need to be evaluated carefully since they represent not one but two different types of enzymic activities which need not necessarily be preserved the same during isolation.

Alternation of physical properties, melting points, molecular volumes etc., of homologous hydrocarbons having odd and even numbers of carbon atoms has been known for many years. This alternation was first thought to be due to the zigzag arrangement of the carbon atoms ${ }^{17}$. However, MAL KIN ${ }^{18,19}$ showed that the alternation of properties of long chain compounds was due to the tilt of the chain with respect to the plane of the terminal group. HUBER ${ }^{20}$ showed that the melting points of the 7- through the I2- octadecenoic acids alternated, and LUTTON AND KOLP ${ }^{21}$ showed that the long and the short spacing of X-ray diffractions of this monoene series also alternated with the odd or even placement of the ethylenic bond. These authors also concluded that the alternations of the long and short spacings and melting points were due to the tilt of the molecules. They believed that the oddnumbered ethylenic bond compounds were "perpendicular (or very nearly so)" and that the even ethylenic bond compounds were "tilted with respect to the carboxyl planes". The results from the comparisons in Table III were quite intriguing, in that they show a correlation between the physical constants of the fatty acids and their acyltransferase activities. An important consideration is that the melting points reflect the hydrocarbon chain interactions in the solid phase, whereas the acyltransferase rates are enzymic activities obtained with solvated or possibly micellar forms of derivatives of fatty acids. Even though the alternating melting points and the $X$-ray diffractions reflect chain-chain interactions, how these interactions would affect the acyltransferase activities is not known. 
In early studies on the enzymic activation of amino acids the enzyme was thought to have a very broad specificity ${ }^{22}$, but the later data of HOAGLAND, KELLER AND ZAMECNIK ${ }^{23}$ suggested the presence of more than one enzyme. This suggestion was subsequently confirmed ${ }^{24}{ }^{26}$, and today it is an accepted fact that there is a specific enzyme for the activation of each amino acid. A similar sequence of events has appeared concerning the specificity of the acid: CoA ligases; however, instead of a ligase for each fatty acid, fatty acid activation is presently grouped into activity for short-(ref. 27), medium-(refs. 28 and 29), and long-chain ${ }^{30-32}$ acids. PANDE AND MEAD ${ }^{32}$ have recently presented data which led to a suggestion that there are at least two long-chain activating enzymes, one for the saturated and one for the unsaturated fatty acids. The activity lost at different rates as the microsomes were aged could be considered to support the suggestion that each fatty acyl-CoA may have its own acyltransferase. However, further purification and separation of enzymic activilies will be necessary to conclusively demonstrate this.

\section{ACKNOWLIDGEMENTS}

This work was supported in part by a grant (AM 053ro) from the U.S. Public Health Service. One of the authors (R.C.R.) is a Postdoctoral Fellow of the National Institutes of Health.

\section{REFERENCES}

I R. C. Reitz, W. E. M. Lands, W. W. Christie and R. T. Holman, J. Biol. Chem., 243 (rg68) $224^{\mathrm{I}}$.

2 W. E. M. Lands, M. L. Blank, L. J. Nutter and O. S. Privett, Lipids, I (1966) 224.

3 P. JezYK AND W. E. M. LANDs, J. Lipid. Res., 9 (1968) 525.

4 F. D. GUNGTONE AND I. A. Ismail, Chem. Phys. Lipids, I (1967) 209.

5 W. Sevbert, Biochem. Prep., 7 (rg6o) 80.

6 G. R. Bartlett, J. Biol. Chem, 234 (1959) 466.

7 W. E. M. Lands and P. Hart, J. Biol. Chem., 240 (1965) rgo5.

80 . Warburg and W. Christian, Biochem. $Z$., 310 (1942) 384.

9 W. E. M. Lands, $J$. Am. Oil Chemists' Soc., 42 (r965) 465.

I0 G. L. ElLMAN, Arch. Biochem. Biophys., 82 (1959) 70.

I W. L. Zaheer, R. E. Barden and W. W. Ceeland, Biochim. Biophys. Acta, 16. (1968) I.

12 N. H. TATtRIE J. Lipid Res., I (1959) 60.

I 3 D. J. Hanahan, H. Brockerhoff and E. J. Barron, J. Biol. Chem., 235 (1960) 1917.

I 4 R. M. Johnson and T. Ito, J. Lipid. Res., 6 (1965) 75.

I 5 K. WAKU AND W. E. M. LANDS, J. Lipid Res., 9 (1968) I2.

16 H. Brockerkoff and R. G. Ackman, J. Lipid Res., 8(1967)66r.

I7 A. Múler, Proc. Roy. Soc. London, Sey. A., 124 (1929) 3 I.

18 T. Malkin, Naiure, 127 (1931) 126.

19 T. Malkin, $J$. Chem. Soc., (1931) 2796.

20 W. I. Huber, J.Am. Chem. Soc, 73 (195I) 2730.

2 I E. S. Lution and D. C. Kolp, J.Am. Chem. Soc., 73 (195I) 2733.

22 M. B. Hoagland, Biochim. Biophys. Acta, I6 (1955) 288.

23 M. B. Hoagland, E. R. Keller and P. C. Zamecnik, J. Biol. Chem., 218 (1956) 345.

24 E. W. Davie, V. V. Koningsberger and F. Lrpmand, Areh. Biochem. Biophys., 65 (1956) 21.

25 P. Berg, J. Biol. Chem., 222 (1956) 1025 .

26 R. S. Schwf.et and F. H. Allfe, J. Biol. Chem., 233 (1958) I 104.

27 L. T. Webster JR., L. D. Gerowin and E. J. Rakita, J. Biol. Chem., 240 (1965) 29.

28 H. R. Mahler, S. J. Wakil and R. M. Bock, J. Biol. Chem, 204 (1953) 453.

29 E. J. MASSARo AND W. J. LenNaRz, Biochemistyy, 4 (1965) 85 .

3o A. Kornberg and W. E. Pricer, J. Biol. Chow, 204 (I953) 329.

3 I J. BAR-TANA AND B. Shapiro, Biochem J., $93(1964) 533$.

32 S. V. Pande and J. F. Mead, f. Biol. Chem., 243 (1968) $35^{2}$. 